\title{
Rosalía de Castro, Manuel Murguía, su hija Aura y el contexto revolucionario de 1868
}

\author{
Rosalia de Castro, Manuel Murguia, their daughter Aura and the revolutio- \\ nary context of 1868
}

Lucía García Vega

lugarvega@gmail.com

[recibido 14/12/2011, aceptado 05/03/2012]

Y la experiencia me enseña, que el hombre que vive, sueña lo que es, hasta despertar. (Calderón de la Barca: La vida es sueño)

\section{RESUMEN}

Esta investigación tiene por objeto cubrir algunos vacíos informativos postergados desde la segunda mitad del siglo XX y que resultan ser claves en los estudios sobre la vida y la producción literaria de Rosalía de Castro (18371885), al tiempo que se le concede una necesaria atención al contexto político en el que se movió su esposo, Manuel Martínez Murguía (1833-1923), en el simbólico año 1868.

Palabras Clave: Rosalía de Castro, Posromanticismo, Manuel Murguía, poesía, literatura de mujer.

García Vega, L. (2012): "Rosalía de Castro, Manuel Murguía, su hija Aura y el contexto revolucionario de 1868". Madrygal (Madr.), 15: 67-76.

\section{RESUMO}

Esta investigación ten por obxecto cubrir algúns baleiros informativos postergados desde a segunda metade do século XX e que semellan ser claves nos estudos sobre a vida e a produción literaria de Rosalía de Castro (18371885), ao tempo que se lle concede unha necesaria atención ao contexto político no que se moveu o seu esposo, Manuel Martínez Murguía (1833-1923), no simbólico ano 1868.

PalabRas ChaVe: Rosalía de Castro, Posromanticismo, Manuel Murguía, poesía, literatura de muller.

García Vega, L. (2012): "Rosalía de Castro, Manuel Murguía, a súa filla Aura e o contexto revolucionario de 1868". Madrygal (Madr.), 15: 67-76.

\section{ABSTRACT}

This research aims to fill some information gaps delayed since the second half of the twentieth century and found to be key studies on the life and literary of Rosalía de Castro (1837-1885), while you are granted a necessary attention to the political context in which it moved her husband, Manuel Martínez Murguía (1833-1923), in the symbolic year 1868 .

KEY WORDS: Rosalía de Castro, post-Romanticism, Manuel Murguía, poetry, women's literature.

García Vega, L. (2012): "Rosalía de Castro, Manuel Murguía, their daughter Aura and the revolutionary context of 1868". Madrygal (Madr.), 15: 67-76. 
SUMARIO: 1 . Introducción. 2. Contexto revolucionario de 1868. 3. Aura Martínez de Castro. 3.1. Documento biográfico inédito. Partida de bautismo de Aura. 3.2. Boda auténtica y boda incierta de Aura. 4. Notas de ecdótica. Poema "¡No sueñes!", génesis de "Tú para mí, yo para ti, bien mío" de En las orillas del Sar (2a ed., 1909). 4.1. Documento bibliográfico inédito. Versión de “¡No Sueñes!” en el Almanaque de Galicia (1867). 4.2. Documento bibliográfico inédito. Versión de “¡No sueñes!” en el Almanaque de El Cascabel (1868). 5. Conclusiones. 6. Referencias bibliográficas.

\section{INTRODUCCIÓN}

Si hubiese que valorar, en términos generales y con la cautela correspondiente, el año 1868 en el transcurso vital del prócer matrimonio formado por Rosalía de Castro y Manuel Murguía, este podría considerarse como un segmento cronológico próspero que habría aportado una aparente estabilidad profesional al historiador, al tiempo que le habría permitido a la gran escritora compostelana hacer acopio de merecidas reseñas sobre sus públicos y notorios méritos literarios.

El mismo año en el que triunfó la revolución iniciada con el alzamiento de Cádiz, también se cumplía el décimo aniversario de su boda celebrada en la iglesia madrileña de San Ildefonso y que había tenido lugar el 10 de octubre de 1858 .

Desde marzo a diciembre de 1868 , un nuevo miembro, Martínez de Castro, crecía dentro de la eximia escritora. Rosalía tenía treinta y un años y había transcurrido casi una década desde su anterior y primeriza maternidad. Y tal vez porque el deseo común era percibir rayos de luz en todas las direcciones, o quizá porque lo que se necesitaba era una exhalación alentadora, cabe la posibilidad de que esta hija fuese bautizada con los nombres de Aura Luz María.

\section{CONTEXTO REVOLUCIONARIO DE 1868}

Así como en otros momentos de las cronologías vitales rosaliana y murguiana es de obligada mención hablar de penurias de diversa índole, y de las que en esta ocasión no nos ocuparemos, el año 1868 semeja ser una rara avis al revisar los principales acontecimientos relacionados con dos de las personalidades gallegas historiables por antonomasia y que, dado el caso, podrían inscribirse perfectamente (Davies 1987: 134) dentro de la conocida con el marbete de Generación de $1868^{1}$.

Si bien es cierto que por estas fechas Rosalía ya era una escritora de acreditada valía, no es menos verdad que su talento literario se acrecentaba cada vez más. De tal forma, el presbítero ourensano Juan Antonio Saco y Arce ${ }^{2}$ (1835-1881), catedrático en el Instituto de Segunda Enseñanza de Ourense, al publicar la primera Gramática gallega (1868) en la imprenta lucense de Soto Freire no vaciló en incluir con el título Cantares dos composiciones del poemario rosaliano Cantares gallegos (1863), en concreto "Miña Santa Margarida" y "Adiós ríos, adiós fontes".

En esta efeméride también habría que recuperar de la bibliografía sobre Rosalía la que probablemente sea la más amplia reseña sobre $E l$ caballero de las botas azules (1867), firmada por Bernardo del Saz y publicada en El Museo Universal el 22 y 29 de febrero de 1868.

También en la geografía catalana se dejaba constancia del interés que suscitaba la obra de Rosalía a través de la publicación de un artículo ${ }^{3}$ sobre Cantares gallegos en la revista Lo Gay Saber, además de realizar la traducción al catalán de cinco de los poemas que integran este texto lírico renombrado y trascendental, por citar algunos ejemplos.

\footnotetext{
${ }^{1}$ Al igual que Davies, aplicamos esta nomenclatura desde un punto de vista histórico. Dado el valor polisémico del concepto, conviene advertir que no utilizamos este término en alusión a una periodización de la literatura. Por tanto, es lógico decir que no es nuestra intención aquí abrir debates acerca de rotular literariamente la obra rosaliana, una observación imprescindible si se tiene en cuenta la convergencia temporal, por ejemplo, del Naturalismo y del Realismo.

2 Se conservan algunas de las cartas remitidas a Murguía, motivadas a raíz de la publicación de la Gramática. Una de ellas es bastante significativa por insinuar que el eminente polígrafo podría estar equivocándose al significarse públicamente en la línea política dominante durante el Sexenio. Veamos un extracto de esta carta remitida el 15 de julio de 1869: "[...] y no se deje alucinar del brillo de modernas ideas que a pesar de la boga que obtienen, no tardarán en desaparecer, ni de los elogios con que por los apasionados a las mismas se ha tratado en algún periódico de atraerle hacia ellas" (Barreiro y Axeitos 2005: 95). El conocido gramático, de ideas opuestas a la Revolución del 68, se había negado a jurar la Constitución de 1869 y fue apartado de su puesto de catedrático.

3 "Bibliografía del moviment literari de certas nacionalitats antigas: Cantars Gallegos", firmado por Francesc Pelai Briz. Véase Hermida (1993).
} 
Mención aparte merece el insólito ascenso profesional de Murguía desde el estallido de la Gloriosa, situación sin parangón, ni antes ni después, a lo largo de su dilatada biografía. A principios de agosto de 1868 , un periódico compostelano recogía el nombramiento del historiador como presidente de la Sociedad para el Fomento de la Historia, Arqueología y Bellas Artes Gallegas, quien previamente se había encargado de la redacción de los estatutos de la referida Sociedad:

Hemos asistido á las tres sesiones que en los días 24, 25 y 26 de Julio tuvieron lugar en el salon de la Sociedad Económica para instalar la de Arqueología y Bellas Artes de Galicia: se discutió el reglamento y despues de varias correcciones y de tratarse muy detenidamente el lugar de su reunión ó congreso anual se constituyó, nombrándose al efecto Presidente al Sr. D. Manuel Murguia, además dos Vice-presidentes, dos Secretarios, varios vocales, un bibliotecario, un mismático, un cronista, etc. (El Eco de la Verdad, $1 / 8 / 1868)$

El 19 de septiembre de 1868 se llevó a cabo en Cádiz la sublevación que supuso el destronamiento de Isabel II (1830-1904) y su consiguiente, al tiempo que consabido, exilio en París, iniciándose el denominado Sexenio Democrático. En un primer acercamiento analítico sobre las consecuencias que tuvo para Murguía el triunfo de la Revolución del 68, no parece que vayamos desorientados si consideramos, inicialmente y sin excesivas minucias, que el cambio político supuso un punto de anclaje en su perdurabilidad laboral; un espejismo que, con el tiempo, le devolvería a la realidad histórica de un país convulso a diversos niveles.

Lo que sí está lejos de toda duda es que la participación del esposo de Rosalía, más o menos activa $^{4}$, según se quiera ver a través de uno u otro cristal, en la destitución de Isabel II le supuso un claro -y con el tiempo caro- rédito profesional. Hoy sabemos que desde el 30 de septiembre hasta el 8 de octubre de 1868 ocupó el cargo de secretario de la recién formada Junta Revolucionaria de Santiago de Compostela (Estrada 1983: 7), cuyo principal cometido era la estampación por escrito de la constitución de la Junta y de la que manuscribió las primeras treinta y dos páginas del Libro de Actas de la Junta Revolucionaria (Cores 1962: 90).

Por disposición de 27 de noviembre de 1868, Murguía era designado Jefe de tercer grado del Cuerpo Facultativo de Archiveros, Bibliotecarios y Arqueólogos, con destino en la villa vallisoletana de Simancas, noticia que tuvo su espacio en la prensa del momento: "D. Manuel Murguía, autor de la Historia de Galicia, ha ingresado en el cuerpo de archiveros-bibliotecarios siendo destinado al archivo de Simancas" (La Correspondencia de España, 30/11/1868).

Este nombramiento fue hecho por su amigo Manuel Ruiz Zorrilla (1833-1895), ministro de Fomento por aquel entonces, a través de una Orden en la que se hacía mención a la idoneidad del reputado coruñés para dicho cargo "por sus méritos literarios, y muy especialmente, por los contraídos en su obra de la Historia de Galicia y en el Diccionario de Autores Gallegos" (Estrada 1983: 6).

De similar forma, a principios de diciembre de 1868 el nombre de Murguía sonaba, tanto en Galicia como fuera de ella, como un posible candidato para las Cortes:

Varios periódicos de Galicia se muestran defensores de la idea de que para las Córtes Constituyentes se elijan á hijos del país probados por su ilustración y patriotismo como el Sr. D. Manuel Murguía, distinguido escritor y autor de la Historia de Galicia, cuyos antecedentes liberales serán una garantía para la causa de la revolución (La Correspondencia de España, 1/12/1868).

\section{AURA MARTÍNEZ DE CASTRO}

El 5 de diciembre de 1868 Murguía tomaba posesión de su nuevo cargo como Jefe de tercer grado del Archivo de Simancas. Esta cuestión indispensable en el estudio biográfico de Rosalía y de su esposo estaría contribuyendo a obtener otra clave informativa esencial. Nos referimos a la preceptiva mención a la ausencia del historiador en el acontecimiento biográfico que puso fin

\footnotetext{
${ }^{4}$ El 9 de septiembre de 1868 le escribía Ramón Rúa Figueroa desde A Coruña una carta a Murguía en la que se percibe a todas luces un uso lingüístico cifrado, un texto que parece esconder entre sus líneas alguna información acerca de la inminente Septembrina: “Acabo de recibir noticias frescas y directas de una persona influyente e interesada en el negocio de las minas. Me dice que dentro de $\underline{10}$ días se promete quede organizada la sociedad pero no dice bajo qué bases" (Barreiro y Axeitos 2005: 44).
} 
al año 1868, es decir, el nacimiento de su hija Aura.

\subsection{DOCUMENTO BIOGRÁFICO INÉDITO. PARTIDA DE BAUTISMO DE AURA}

La segunda hija del matrimonio nació el 7 de diciembre de 1868 en la casa que llevaba el número 40 de la calle Callobre de Santiago de Compostela 5 . Por consiguiente, convendría fijar 1868 como la data real en la que tuvo lugar este nacimiento y su posterior bautismo, y no 1869 como en algunos sitios se puede leer 6 .

Fue bautizada al día siguiente en la parroquia compostelana de San Fiz de Solovio con los nombres de Aura María Luz, por lo que, a partir de ahora, sería recomendable descartar otras alusiones $^{7}$ nominales para referirse a esta hija ${ }^{8}$. La inscripción eclesiástica dice así:

Aura Maria Luz Martinez hixa de $\mathrm{D}^{\mathrm{n}}$ Manuel y D. ${ }^{a}$ Rosalía de Castro su Mujer. En el dia ocho de Diciembre del año de mil ochocientos sesenta y ocho Yo el Presbitero D. ${ }^{\mathrm{n}}$ Antonio Suarez y Vazq Cura Parroco de las Yglesias Parroq. ${ }^{\mathrm{s}}$ de $\mathrm{S}^{\mathrm{n}}$ Felix de Solobio y Santa Maria Salomé en esta Ciud. de Santiago Prov. ${ }^{\text {a }}$ de la Coruña bauticé solemnem ${ }^{\text {te }}$ y puselos S. ${ }^{\text {tos }}$ oleos a una Niña q. ${ }^{\mathrm{e}}$ nació el dia anterior y hora de diez de la mañana en la Calle de Callobre y casa del numero cuarenta es hixa de D. ${ }^{\mathrm{n}}$ Manuel Martinez Murguia natural de la de Santa Maria de Pastoriza y su Mujer D. ${ }^{\text {a }}$ Rosalia de Castro oriunda de esta referida de Santiago su profesión Literato. $\mathrm{Ab}^{\mathrm{s}}$. Paternos $\mathrm{D}^{\mathrm{n}}$. Juan Martinez y $\mathrm{D}^{\mathrm{a}}$. Concepon. Murguia de la propia de Santiago. Maternos $\mathrm{D}^{\mathrm{a}}$. Teresa de Castro. Pusele nombre Aura Maria Luz de la qual fueron sus Padrinos $\mathrm{D}^{\mathrm{n}}$. Ramon Campo Hermida vecino de Padron y $\mathrm{D}^{\mathrm{a}}$. Alexandra Martinez Murguia hermana de la bautizada aquienes he advertido el Parentesco espiritual y las demás obligacions ${ }^{\mathrm{s}}$. $\mathrm{q}^{\mathrm{e}}$. Previene el Ritual Romano. Y para $\mathrm{q}^{\mathrm{e}}$. conste lo firmo fecha utsupra [rúbrica] ${ }^{9}$.
Según una nota manuscrita por el propio Murguía, la elección del nombre Aura pudo obedecer a que "hay esta santa. En el P. Flórez, tomo II, página 86 , se dice que había hacia mediados del siglo XII, una religiosa -Aura Bellide- que fundó el monasterio de Santa Eulalia de Morgadáns" (Naya 1998: 152).

Y efectivamente así se registra en el texto del Padre Flórez, si bien nos hemos percatado de un pequeño detalle que quizá pudiera tener algo que ver con la decisión de bautizar a esta hija con dicho nombre. A cada uno de los versículos que componen los capítulos de la obra de Flórez le antecede un número ordinal. En el capítulo 6 dedicado a la "Restauración del obispado de Tuy, y sus obispos hasta el Siglo XIII" se puede comprobar que el párrafo que da comienzo con " 68 " justamente es el que Murguía había anotado, coincidiendo con el año 1868 en que había nacido Aura:

68 Habia una Religiosa, llamada Doña Aura Bellide, que vivía con otras: y queriendo fundar un Monasterio Benedictino en la Villa de Sta Eulalia, territorio de Morgadanes, ó Mogardos, obtuvo del Emperador donación de la misma Villa para la fundación, confirmándola el Obispo D. Pelayo con otros, dia 23 de Abril, tertio mense post mortem Imperatricis Berengaria, Era 1187. año 1149. Dada en Salamanca. La nota de la muerte de la Emperatriz sale bien: porque falleció en Febrero de aquel año 1149. como digimos en el Tomo I de las Reynas (Flórez 1767: 86-87).

\subsection{BODA AUTÉNTICA Y BODA INCIERTA DE AURA}

Los datos biográficos que se tienen sobre Aura son muy escasos, situación que poco o nada tiene de excepcional, puesto que una tesitura idéntica podría ampliarse a los casos, más o menos especiales, de sus hermanos. Desde esta perspectiva, cotejable por cualquier individuo que se tome la molestia de, al menos, hojear, por ejemplo, un

\footnotetext{
${ }_{6}^{5}$ Para cuestiones puntuales biográficas, véase García Vega (2011).

${ }^{6}$ Filgueira (1974: 30), Martí (1977: 80), Tirrell (1951: 37).

7 Leemos "María Aurora" en Bouza (1962: 375) y "Aurora" en Mayoral (1986: 35). También hemos encontrado el apelativo “Aurea" en Martí (1944: 80) y en Tirrell (1951: 37).

${ }^{8}$ Ricardo Carballo Calero, refiriéndose a esta segunda hija de Rosalía, tenía confianza en que fuese Fermín Bouza Brey el que "publique esa partida dun momento a outro" y que ya le había adelantado que Aura "non é senón diminutivo familiar de María Aurora, contra o que outros eruditos cren" (Carballo 1964; 1979: 89). Finalmente Bouza Brey no publicó esta partida y es probable que ni siquiera hubiese tenido acceso a ella, por lo menos a la de bautismo que en este artículo se difunde. La razón es obvia, y es que si hubiese tenido conocimiento de la partida bautismal, en primer lugar, la habría dado a conocer como hizo con otras y, en segundo lugar, no se habría cuestionado que el nombre de esta hija de Rosalía fuese "María Aurora" (Bouza Brey 1962: 375).

${ }^{9}$ Archivo Histórico Diocesano de Santiago de Compostela. Parroquia de San Fiz de Solovio.
} 
completo y esmerado estudio biobibliográfico rosaliano ${ }^{10}$, semeja lícito admitir, una vez más, la predisposición a no hallar noticias en abundancia acerca de los miembros de la familia Murguía-De Castro, unas informaciones que parecen estar cubiertas figuradamente por un compacto tegumento de enigmas y cábalas, aparte de otras cosas, muchas veces disuasorio para el investigador por su porosidad insuficiente.

Algunos aspectos que se conocen sobre Aura proceden del testimonio de Naya Pérez, una fuente reveladora con garantías dada la amistad que tuvo con la familia y, por tanto, sujeto testimonial al que siempre conviene recurrir.

Sabemos que Aura se casó por poderes con el alicantino Francisco Prats Pérez, ceremonia celebrada en la parroquia coruñesa de San Nicolás el 30 de agosto de 1897, noticia de la que se hizo eco la prensa del momento:

En la parroquia de San Nicolás de la Coruña, contrajo matrimonio la señorita Aura Martinez Murguia con el comerciante de Yecla (Murcia) don Francisco Prats quien no asistió al acto, enviando en su representación al comandante de Infantería don Angel Romero.

Dicha señorita hija de la nunca bien llorada poetisa gallega Rosalía Castro, residió con su familia varios años en Santiago. (Gaceta de Galicia, 1/9/1897)

Francisco Prats se dedicó durante algún tiempo a trabajar en el ámbito periodístico, por lo menos hasta 1902, fecha en la que dejaba su puesto de director de un periódico manchego:

En íntima jira campestre han despedido hoy los redactores de la prensa local al ilustre periodista D. Francisco Prats Pérez, que se ausenta de esta población, abandonando la dirección del Heraldo de Albacete.

Ha reinado entre los reunidos la más franca intimidad, brindando todos por el Sr. Prats, que ha sabido captarse aquí generales simpatías". ( $L a$ Correspondencia de España, 1/7/1902)

Aparte de esto, Prats desarrolló la mayor parte de su actividad profesional ocupando el puesto de interventor de fondos municipales, cargo que le obligó a cambiar constantemente de lugar de residencia ${ }^{11}$.

Volviendo a la figura de Aura, aunque desconocemos exactamente a qué fue debido este equívoco ${ }^{12}$, dos años antes de celebrarse el matrimonio de la segunda hija de Rosalía y de Murguía, se divulgó la falsa noticia de una supuesta boda entre ella y el notario José Barreiro Meiro:

Dentro de breve tiempo contraerá matrimonio la Srta. Aura Martinez Murguía, hija de la tan llorada poetisa gallega Rosalía Castro, con el aventajado joven notario en la Puebla del Brollón, alumno que fué de la Universidad de Santiago, D. José Barreiro Meiro. (Eco de Galicia, 7/3/1895)

Fue el propio Barreiro Meiro el que solicitó la publicación de un desmentido a este respecto. Tres días más tarde el mismo periódico rectificaba e incluía la información siguiente: "Nos escribe el señor Barreiro Meiro, rogándonos desmintamos la noticia del casamiento que se anunciara de dicho señor con la señorita Aura Martinez Castro. Queda complacido nuestro estimado amigo" (Eco de Galicia, 10/3/1895).

Lo último que sabemos es que los restos de Aura y de su esposo fueron traídos desde Carmona (Sevilla) para ser inhumados en el panteón familiar de A Coruña el 7 de noviembre de 1959 (Naya 1998: 154).

\section{NOTAS DE ECDÓTICA. POEMA “¡NO SUEÑES!", GÉNESIS DE "TÚ PARA MÍ, YO PARA TI, BIEN MÍO" DE EN LAS ORILLAS DEL SAR (2 ${ }^{\mathrm{a}}$ ED., 1909)}

El año 1868, además de ser productivo para Rosalía en el ámbito personal, según hemos visto en los epígrafes anteriores, le sirvió de plataforma para modelar una versión de un poema que finalmente se integró en una edición póstuma, y cuyo germen lírico habría que buscarlo en 1867.

Se trata de la composición "Tú para mí, yo

\footnotetext{
10 Véase López y Pociña (1991, 1993). De los mismos, Pociña y López (2000).

11 Algunos de sus destinos fueron A Coruña, Puente Genil (Córdoba), Sanlúcar de Barrameda (Cádiz), Cullera (Valencia), Totana (Murcia) o Morón de la Frontera (Sevilla).

12 Se nos ocurre que el único punto (hipotético) de conexión entre ambos pudo ser la imprenta y librería de Carré en A Coruña. José Barreiro Meiro publicó Harmonías jurídicas en 1894 en esta imprenta coruñesa, mientras que Manuel Murguía sacaba a la luz En prosa en 1895 en la misma casa editorial. Dada la cercanía de fechas y la posibilidad de coincidir en la corrección de pruebas, pudiera ser que la confusión partiese de un fortuito encuentro y, a su vez, este podría haber sido el motivo de la divulgación de un irreal noviazgo.
} 
para ti, bien mío", ejemplo de motivo becqueriano (Nogales 1966: 157), exenta de título que la identifique, y que fue añadida por Murguía a la segunda edición del poemario En las orillas del Sar, indicando solo el año 1867 a modo de datación de estos versos de Rosalía. En algunas de las posteriores ediciones de esta obra lírica se tomó como texto base el poema que el historiador había fechado en dicho año, sin más datos informativos acerca de la composición.

Ahora bien, si lógico era proponer una necesaria anotación temporal de los poemas que formaron En las orillas del Sar (Mayoral 1985: 30), no menos razonable parece ser el planteamiento de algunos enigmas acerca de la ecdótica de este texto rosaliano, a veces motivados por sospechas fundadas, tal y como podrían ser una sencilla distracción cronológica sin más o un elocuente silencio informativo que poco o nada tendría de impremeditación.

En el caso del poema iniciado por el verso "Tú para mí, yo para ti, bien mío", tenemos el privilegio de dar a conocer a través de estas líneas dos versiones desconocidas de este texto, publicadas con muy poca diferencia cronológica (un año). Ambas, y aquí viene lo curioso, aparecieron con el título “¡No sueñes!” que Murguía, una vez más adulterando el texto genuino de su esposa, consideró$^{13}$ que debía desaparecer en la segunda edición del que fue el último poemario de Rosalía.

\subsection{DOCUMENTO BIBLIOGRÁFICO INÉDI- TO. VERSIÓN DE “¡NO SUEÑES!” EN EL ALMANAQUE DE GALICIA $(1867)^{14}$}

En una ocasión decía Bouza Brey acerca de la génesis de En las orillas del Sar que, aparte del excedente lírico de Follas novas y que Rosalía tradujo al castellano, se habrían agregado poemas dispersos en castellano como "A la luna", publicado ya en 1867 (Bouza 1961). Como pasa a menudo al tratar la (bio)bibliografía de Rosalía, de nuevo surge un sinfín de incógnitas, en particular acerca de la decisión de no incluir, por ejemplo, otro poema también disperso, en castellano y datado en 1867, en el último libro publicado en vida de la de Compostela. Nos referimos a la composición que inicialmente apareció con el título “¡No sueñes!" (1867) en el famoso Almanaque de Galicia y que se imprimía en los talleres lucenses de Soto Freire ${ }^{15}$.



Poema “¡No sueñes!” en el Almanaque de Galicia (1867)

\footnotetext{
13 Desconocemos la motivación real de dicha adulteración. En este sentido, podría ser perfectamente válida la hipótesis que Mayoral manejaba al respecto, toda vez que por aquel entonces no se conocían aún algunos de los datos biobibliográficos acerca de la escritora que hoy sí están al alcance del investigador atento: "Murguía en 1909 era ya demasiado viejo y los tiempos habían cambiado bastante como para que los prejuicios que impidieron en 1884 publicar versos demasiado transparentes se hubieran desvanecido" (Mayoral 1969: 13).

14 Este número se corresponde con el año quinto de la publicación, es decir, 1868. El título completo era Almanaque de Galicia, para uso de la juventud elegante y de buen tono dedicado á todas las bellas hijas del país.

15 Nótese que también el mismo editor imprimió en 1867 la novela El caballero de las botas azules.
} 


\subsection{DOCUMENTO BIBLIOGRÁFICO INÉDI- TO. VERSIÓN DE “¡NO SUEÑES!” EN EL ALMANAQUE DE EL CASCABEL (1868)}

Tal y como su nombre indica, esta publicación, editada por el periódico madrileño $E l$ Cascabel ${ }^{16}$, era un calendario con santoral acompañado de notas astronómicas, relación de fiestas y profecías para el año en cuestión, así como continente de narraciones, poemas, epigramas y letrillas. Normalmente los textos solían aparecer animados con dibujos, muchos de ellos en clave humorística, además de insertar grabados, retratos de monumentos y de escritores célebres, biografías de personajes históricos y anuncios publicitarios.

El Almanaque de El Cascabel para 1869 vio la luz en la Imprenta de Carlos Frontaura ${ }^{17}$, a cuyo frente estaba Diego Valero, y que por esas fechas se ubicaba en el número 4 de la calle Hileras. De la lista de colaboradores de este año, habría que prestar especial atención a dos nom- bres de los que allí hay, al ya mencionado Frontaura $^{18}$ y a Julio Nombela ${ }^{19}$, puesto que ambos pertenecieron al círculo de conocidos de Rosalía y Murguía en sus estancias en Madrid. La primogénita del matrimonio, Alejandra ${ }^{20}$, tiempo después declaraba acordarse de la época ${ }^{21}$ en que viviendo allí con sus padres "coñecimos aos dous irmáns Becquer. Tamén a Frontaura, Teodoro Guerrero, Federico Balart, Julio Nombela" (Risco 1976: 15).

En 1867 Nombela había reseñado la novela $E l$ caballero de las botas azules en un espléndido artículo publicado en La Época, de la que decía, entre otras cosas, que "toda nuestra época está retratada en El caballero de las botas azules; este personaje es el siglo XIX; la autora es la posteridad que le juzga", y catalogando la obra de ser "un libro trascendental, un libro que hoy seria apreciado en mucho; pero no en tanto como lo apreciaran los que le lean en el siglo XX" ( $L a$ Epoca, 7/11/1867), a lo que podría añadirse que sigue estando vigente en el siglo XXI también.



Poema “¡No sueñes!” en el Almanaque de El Cascabel (1868)

\footnotetext{
${ }^{16}$ El primer número apareció en 1863. En el año 1868 llevaba el subtítulo Diario festivo, político y literario hasta el 1 de octubre. A partir de esta fecha se editó con el subtítulo Político y literario. El director y editor era Carlos Frontaura, y el cargo de administrador lo ostentó Francisco Perezagua.

17 Periodista, poeta y dramaturgo madrileño, nacido en 1834 y fallecido en 1910.

18 Como si estuviese hecho adrede, la única vez que Frontaura editó algo de Rosalía fue este año 1868. Asombrosamente la casualidad llega a tal punto que este apellido contiene el nombre 'Aura': Front ('aura').

19 Escritor y periodista madrileño, nacido en 1836 y fallecido en 1919.

${ }^{20}$ Nació en 1859 en Santiago de Compostela y falleció en 1937 en A Coruña.

${ }^{21}$ Entre 1870 (incluso puede que algún tiempo hacia el final de 1869) y 1871 ocuparon la vivienda número 13 de la calle Claudio Coello. Sobre estancias de Rosalía en Madrid, véase García Vega (2010).
} 


\section{CONCLUSIONES}

A juzgar por la documentación generada y que ha ido saliendo a la luz, se puede decir que el año 1868 fue bastante fértil, y nunca mejor dicho, tanto para Rosalía de Castro como para Manuel Murguía, si bien con obvias diferencias entre los cónyuges, aunque sí compartiendo la calidad efímera del éxito que con el paso del tiempo acabaría por convertirse en irremediable decadencia ${ }^{22}$.

En diciembre de 1868 nacía la segunda hija del matrimonio en Santiago de Compostela, y todo parece indicar que Murguía no estuvo presente en este evento. De hecho, la revisión esmerada de los informes tramitados en esas fechas y rubricados por el nuevo Jefe del Archivo simanquino, es decir, por Murguía, estaría indicándonos, con un alto grado de probabilidad de que así fuese, que el esposo de Rosalía tal vez conoció a su nueva hija no antes del 15 de enero de 1869. El 12 de enero de 1869 se le comunicaba la concesión de un mes de licencia para recobrar su supuesta $^{23}$ maltrecha salud. De esta manera, el 15 de enero de 1869 el ya archivero le escribía al Rector de la Universidad de Valladolid:

Siendo forzoso para reparar mi salud tener que hacer uso del mes de licencia que se me ha concedido por la Dirección General de Instrucción Pública con fecha 2 del actual, pongo en conocimiento de V.S. que desde hoy doy principio a ella, así como también de quedar encargado de la Dirección de este Archivo el oficial de más graduación D. Francisco Díaz Sánchez. (Estrada 1983: 7-8)

Asimismo, en 1868 el prestigio literario de Rosalía iba en aumento y se propagaba por diversas lenguas y geografías. Un ejemplo claro es que fue invitada a participar en lo que algunos medios denominaron la fiesta de la poesía catalana:

En cuanto á los poetas castellanos, se ignora todavía quienes se dignarán asistir. Entre los invitados figuran la poetisa gallega D. ${ }^{a}$ Rosalía Castro de Murguía y el Sr. Nuñez de Arce que se halla actualmente en Barcelona. Una comisión de escritores catalanes pasará á Lérida á recibir á los poetas de Castilla, en caso de que alguno corresponda á la invitación. (Diario Oficial de Avisos de Madrid, 23/4/1868)

Por otra parte, habría que remontarse a mediados del siglo pasado para conocer algo sobre lo que pudo haber sido el desarrollo de la composición "¡No sueñes!" en la mente de la poeta, momento en el que se hacía pública una versión manuscrita (Tirrell 1951)24. En este borrador Rosalía iniciaba el poema a través del verso "Es el amor la esencia de la vida", pero no aparece rastro del título y que sí se registró en las versiones de 1867 y de 1868 .

Se ha comprobado que inicialmente el poema fue estructurado en tres partes, de las cuales la segunda fue tachada por la poeta y que resultó ser un fragmento del texto que "está impregnada de la tristeza necesaria" para darle "la clave a la composición" (Tirrell 1951: 341). En la versión de 1867 del Almanaque de Galicia el texto tomó forma en base a dos partes, bien diferenciadas con numeración romana. Por su parte, la versión de 1868 del Almanaque de El Cascabel está formada por 30 versos seguidos y sin ningún tipo de separación o distinción estrófica.

En fechas no muy distantes a la importante aportación hecha por Tirrell, gracias al gesto desinteresado y plausible que Naya tuvo al cederle el texto para que ella lo publicase, creía Machado da Rosa que "apenas existen poemas de En las orillas del Sar anteriores a los años 18701871" (Machado 1957: 98), quien daba a conocer una versión del poema "A la luna" de En las orillas del Sar; si bien habría que certificar hoy que este poema se publicó en 1866 y no en 1867 . Y razón no le faltaba porque así ha sido durante mucho tiempo. No obstante, dentro de esas excepciones que este crítico parecía intuir, habría que insertar las dos versiones de “¡No sueñes!” que se dan a conocer en este artículo.

También la situación particular que describe el

\footnotetext{
22 Seis años después, al fracasar la revolución y proclamarse la Restauración, Murguía fue cesado de sus funciones, concretamente el 23 de febrero de 1875, aunque sus problemas laborales venían de años anteriores. En el caso de Rosalía se puede constatar a las claras el lapsus, si no creativo, sí editorial, que va desde la publicación de un poema en 1868, y que damos a conocer en este artículo, hasta la segunda edición, aumentada, de Cantares gallegos en 1872. Parece, pues, que hubo una pérdida de poder social, al tiempo que, en el caso de Murguía, una desaparición de la escena política.

23 Parece ser que el galeno Marcial Taboada de la Riva, amigo de la infancia de Murguía, podría haber sido la persona que le extendió certificados médicos exagerados al marido de Rosalía, los cuales le permitieron pasar, por qué no decirlo, desmedidas y poco creíbles temporadas fuera de Simancas. Véase Barreiro y Axeitos (2005: 143).

24 Véase Naya (1953: 17) y Tirrell (1951: 337).
} 
poema "Tú para mí, yo para ti, bien mío" podría extenderse perfectamente a la mayor parte de la obra literaria de Rosalía, en la que subyace una "evolución incipiente y progresiva, pero siempre intensa y vigorosa, de un mismo estado de ánimo, concentrado en un tema obsesivo: amor desgraciado" (Nogales 1966: 25).

Refiriéndose al mismo poema, otra crítica interpretaba que este es "el texto que mejor reproduce lo que fue la postura final de Rosalía ante el amor" (Mayoral 1986: 88) ${ }^{25}$. Si se tiene en cuenta que en aquellos momentos se desconocía la existencia de un título ilustrativo como es "¡No sueñes!" -y que estas serían las primeras palabras con las que los ojos lectores se toparían-, Mayoral explicaba con claridad meridiana lo que, probablemente, fuese la actitud personal de Rosalía ante el amor:
En muchos otros poemas encontramos la misma idea: el amor es una más de las ilusiones juveniles que el tiempo destruye, pero en ninguno de ellos expresó de forma tan explícita esa evolución desde la creencia inicial en un amor único, fuente de vida y de felicidad, a la amarga resignación de la mujer que, en el invierno de su vida, acepta valerosamente su destino de soledad y desamor. (Mayoral 1986: 88)

Rosalía en torno a 1867 y 1868 , ya alejada de la ensoñación de otra época, invitaba a pensar en la cara más realista de la vida. El manifiesto pesimismo ante el amor que emerge en " $¡$ No sueñes!" podría estar advirtiendo de manera enérgica de la inutilidad de representar en la mente la ilusión en el amor.

\section{REFERENCIAS BIBLIOGRÁFICAS}

Barreiro Fernández, Xosé Ramón y Xosé Luís Axeitos (2003): Cartas a Murguía. A Coruña: Fundación Barrié de la Maza. (2005): Cartas a Murguía II. A Coruña: Fundación Barrié de la Maza.

BouZA Brey, Fermín (1962): "Adriano y Valentina, motivaciones inspiradoras de Rosalía de Castro", Cuadernos de Estudios Gallegos, n. ${ }^{\circ}$ 53. Santiago de Compostela: Instituto Padre Sarmiento de Estudios Gallegos, pp. 374-390.

Carballo Calero, Ricardo (1964): "Bibliografía rosaliana", Grial, n. ${ }^{\circ} 3$. Vigo: Galaxia, pp. 119-121. (1979): Estudos rosalianos. Aspectos da vida e da obra de Rosalía de Castro. Vigo: Galaxia. (1981): Historia da literatura galega contemporánea 1808-1936. Vigo: Galaxia.

Cores Trasmonte, Baldomero (1962): "La revolución de septiembre en Compostela", Cuadernos de Estudios Gallegos, n. ${ }^{\circ}$ 51. Santiago de Compostela: Instituto Padre Sarmiento de Estudios Gallegos, pp. 90-116.

DAVIES, Catherine (1987): Rosalía de Castro no seu tempo. Vigo: Galaxia.

Estrada NéRIDA, Julio (1983): Páginas de una biografia: Manuel Murguía, director del Archivo de Simancas (1868-1870). Sada (A Coruña): Ediciós do Castro.

Filgueira Valverde, José (1974): Con Rosalía de Castro en su hogar. Vigo: Patronato Rosalía de Castro.

FlóREZ, Fr. Henrique (1767): España Sagrada, teatro geographico-historico de la Iglesia de España. Origen, divisiones, y límites de todas sus Provincias. Antigüedad, Traslaciones, y estado antiguo y presente de sus Sillas, con varias Disertaciones críticas, tomo XXII. Madrid: Antonio Marín.

GARCía MARTí, Victoriano (1977): "Rosalía de Castro o el dolor de vivir", en Victoriano García Martí (ed.), Obras completas de Rosalía de Castro. Madrid: Aguilar, t. I, pp. XI-CCL.

GARCíA VegA, Lucía (2010): "Rosalía de Castro e Madrid. Análise literaria dos lugares na novela El caballero de las botas azules (1867)", Moenia, n. ${ }^{\circ}$ 16. Lugo: Universidade de Santiago de Compostela, pp. 195-245.

(2011): "Rosalía de Castro agonista. Diálogos protagonista y antagonista con la ciudad de Santiago de Compostela", Ángulo Recto. Revista de estudios sobre la ciudad como espacio plural,

\footnotetext{
25 Sobre este asunto, véase Mayoral (1985: 8).
} 
vol. 3, no. 2, pp. 51-67. En: http://www.ucm.es/info/angulo/volumen/Volumen03-2/articulos04.htm. ISSN: 1989-4015 http://dx.doi.org/10.5209/rev_ANRE.2011.v3.n2.37579.

Hermida Gulías, Carme (1993): Rosalía de Castro na prensa barcelonesa (1863-1899). A Coruña: Patronato Rosalía de Castro.

LÓPEZ, Aurora y Andrés PociÑa (1991): Documentación biográfica y bibliografía crítica (1837-1990), vols. I-II. A Coruña: Fundación Pedro Barrié de la Maza.

(1993): Documentación biográfica y bibliografía crítica (1837-1990), vol. III. A Coruña: Fundación Pedro Barrié de la Maza.

MACHADO DA ROSA, Alberto (1957): "Subsidios para la cronología de la obra poética rosaliana", Cuadernos de Estudios Gallegos, n. ${ }^{\circ}$ 36. Santiago de Compostela: Instituto Padre Sarmiento de Estudios Gallegos, pp. 92-106.

MARTínez BARBeito, Carlos (1949): "Ovidio Murguía y sus hermanas. Un negro disparó sobre Rosalía durante una revuelta en la Corte", La Noche. Santiago de Compostela, 19/11/1949.

MAYORAL, Marina (1969): "Sobre el amor en Rosalía de Castro y sobre la destrucción de ciertas cartas", Cuadernos Hispanoamericanos, n. ${ }^{\circ}$ 233. Madrid: Instituto de Cooperación Iberoamericana, pp. 116.

(1976): Rosalía de Castro y sus sombras: conferencia pronunciada en la Fundación Universitaria Española el día 21 de abril de 1975 con motivo del Año Internacional de la Mujer. Madrid: Fundación Universitaria Española.

(1985): Edición de En las orillas del Sar. Madrid: Castalia.

(1986): Rosalía de Castro. Madrid: Cátedra.

NAYA PÉRez, Juan (1953): Inéditos de Rosalía. Santiago de Compostela: Patronato Rosalía de Castro. (1998): Estudios acerca de la familia Murguía-Castro. A Coruña: Deputación Provincial da Coruña.

Nogales de MuÑIz, María Antonia (1966): Irradiación de Rosalía de Castro. Palabra viva, tradicional y precursora. Barcelona: Ángel Estrada.

PocinA, Andrés y Aurora LóPez (2000): Rosalía de Castro. Estudios sobre a vida e a obra. Santiago de Compostela: Laiovento.

RÉPIDE, Pedro de (2005): Las calles de Madrid. Madrid: La Librería (1 ${ }^{\mathrm{a}}$ ed. 1921-1925).

RisCo, Vicente (1976): Manuel Murguía. Vigo: Galaxia.

SACO Y ARCE, Juan Antonio (1868): Gramática gallega. Lugo: Imprenta de Soto Freire.

TIRRELL, Sister Mary Pierre (1951): La mística de la saudade. Madrid: Jura. 